\title{
TECNOLOGIAS APLICADAS À CONSERVAÇÃO DO PATRIMÔNIO EDIFICADO DA FIOCRUZ
}

\author{
COELHO, Carla
}

Fundação Oswaldo Cruz, Casa de Oswaldo Cruz, Departamento de Patrimônio Histórico, e-mail: carla.coelho@fiocruz.br

OLIVEIRA, Benoni

Fundação Oswaldo Cruz, Casa de Oswaldo Cruz, Departamento de Patrimônio Histórico, e-mail: benoni.oliveira@fiocruz.br

\section{ANDRADE, Inês}

Fundação Oswaldo Cruz, Casa de Oswaldo Cruz, Departamento de Patrimônio Histórico, e-mail: ines.andrade@fiocruz.br

\section{MENDES, Fernando}

Fundação Oswaldo Cruz, Casa de Oswaldo Cruz, Departamento de Patrimônio Histórico, e-mail: fernando.mendes@fiocruz.br

\section{SÁ, Bruno}

Fundação Oswaldo Cruz, Casa de Oswaldo Cruz, Departamento de Patrimônio Histórico, e-mail: bruno.sa@fiocruz.br

\begin{abstract}
RESUMO
O artigo discute as dificuldades no desenvolvimento de um sistema de informação para edificações históricas, com vistas a um adequado modelo de planejamento de inspeção, monitoramento e intervenções. Integra uma pesquisa ainda em etapa inicial no âmbito do Departamento de Patrimônio Histórico da Casa de Oswaldo Cruz da Fundação Oswaldo Cruz. Apresenta os principais objetivos do estudo, traça as experiências e dificuldades de um escritório técnico especializado em preservação do patrimônio edificado de cunho institucional e aponta perspectivas futuras para o aprimoramento do planejamento das ações de conservação.
\end{abstract}

Palavras-chave: Patrimônio edificado, Documentação, Conservação Preventiva.

\begin{abstract}
The paper discusses the difficulties in developing an information system for historical buildings, aiming to stablish an adequate model of inspection, monitoring and interventions planning. It integrates a research still in an initial stage within the scope of the Department of Historic Patrimony of the Oswaldo Cruz House of the Oswaldo Cruz Foundation. It presents the main objectives of the study, traces the experiences and difficulties of a technical office specialized in the preservation of the institutional built heritage and points out future perspectives for the improvement of conservation actions planning.
\end{abstract}

Keywords: Built heritage, Documentation, Preventive conservation.

\section{INTRODUÇÃO}

A Fundação Oswaldo Cruz (Fiocruz), instituição centenária sediada em Manguinhos, no Rio de Janeiro, tem uma consolidada atuação na área da saúde. Para gerir seus campi necessita de diversos escritórios técnicos de

COELHO, C.; OLIVEIRA, B.; ANDRADE, I.; MENDES, F.; SÁ, B. Tecnologias aplicadas à conservação do patrimônio edificado da Fiocruz. In: SIMPÓSIO BRASILEIRO DE QUALIDADE DO PROJETO NO AMBIENTE CONSTRUÍDO, 6., 2019, Uberlândia. Anais... Uberlândia: PPGAU/FAUeD/UFU, 2019. p. 790-800. DOI https://doi.org/10.14393/sbqp19073. 
arquitetura e engenharia. Na área de preservação arquitetônica destaca-se a atuação do Departamento de Patrimônio Histórico (DPH), estabelecido desde 1989 na unidade Casa de Oswaldo Cruz (COC). O DPH é responsável pelas ações de preservação de parte do acervo arquitetônico e urbanístico da instituição localizado no campus Manguinhos, totalizando aproximadamente $20.000 \mathrm{~m}^{2}$ de área construída. Também atua de forma colaborativa com outras unidades da instituição que possuem escritórios técnicos de arquitetura e engenharia em ações relacionadas a edificações e áreas históricas cuja gestão da conservação é compartilhada.

Muitas das edificações sob responsabilidade do DPH fazem parte do Núcleo Arquitetônico Histórico de Manguinhos (NAHM), idealizadas no início do século XX para abrigar as atividades laboratoriais e de criação de animais necessárias à produção de soros e vacinas, com destaque para os exemplares tombados pelo Instituto do Patrimônio Histórico e Artístico Nacional - IPHAN em 1981: Pavilhão Mourisco (1918), antigo Pavilhão da Peste, atual Pavilhão do Relógio (1905), e a Cavalariça (1904) [Figura 1]. Ainda integram o conjunto eclético o Pavilhão Figueiredo de Vasconcellos (1919-1921), a Casa de Chá (1905) e Restaurante Anexo (1920), O Hospital Evandro Chagas (1918), o Pombal (1904) e a Casa Amarela (1922). Também são consideradas edificações de interesse para a preservação o conjunto modernista composto pelo antigo Restaurante Central, atual Pavilhão Carlos Augusto da Silva (1951) e o antigo Pavilhão de Cursos, hoje conhecido como Pavilhão Arthur Neiva (1947), tombados pelo Instituto Estadual de Patrimônio Cultural do Estado do Rio de Janeiro - INEPAC. Fazem parte deste conjunto ainda a portaria da Av. Brasil (1954) e o Laboratório da Febre Amarela (1956), ambos incluídos em um recente dossiê encaminhado ao INEPAC com o pedido de extensão do tombamento.

As atividades do DPH abrangem o desenvolvimento de pesquisas, a elaboração de projetos de restauração e de planos de conservação preventiva, o acompanhamento e fiscalização das obras e serviços executados e a realização de ações de educação patrimonial. As obras de restauração, bem como as ações contínuas de conservação e manutenção civil são executadas por empresas terceirizadas sob supervisão dos técnicos do $\mathrm{DPH}$.

A partir da experiência de fiscalização das ações contínuas de conservação realizadas desde o início dos anos 2000, a equipe do DPH desenvolveu uma metodologia para realização de inspeções periódicas e definição das ações a serem adotadas considerando três tipos de abordagens: conservação preventiva; conservação curativa ou restauração (Pinheiro et al., 2009). Especial atenção tem sido dada à conservação preventiva, definida pela política de preservação institucional como um conjunto de ações que visam evitar a deterioração e a perda de valor dos bens culturais, englobando pesquisa, documentação, inspeção, monitoramento, conservação programada e planos de contingência (Fundação Oswaldo Cruz. Casa de Oswaldo Cruz, 2013). Apesar dos avanços já alcançados em relação à priorização da abordagem preventiva, em decorrência do grande volume de trabalho e do quadro reduzido de recursos humanos, muitas das ações realizadas nas edificações históricas ainda podem ser caracterizadas como de conservação curativa ou restauração. 
Considerando a necessidade de aprimoramento das estratégias de inspeção e monitoramento a equipe do DPH tem buscado incorporar novas ferramentas e tecnologias às suas rotinas de trabalho visando à melhoria dos processos relacionados à conservação das edificações históricas e à otimização do tempo da equipe. Ao longo do trabalho apresentaremos ações já implementadas bem como algumas que se encontram em processo de teste e analisaremos as perspectivas futuras para atingir os objetivos definidos pela equipe.

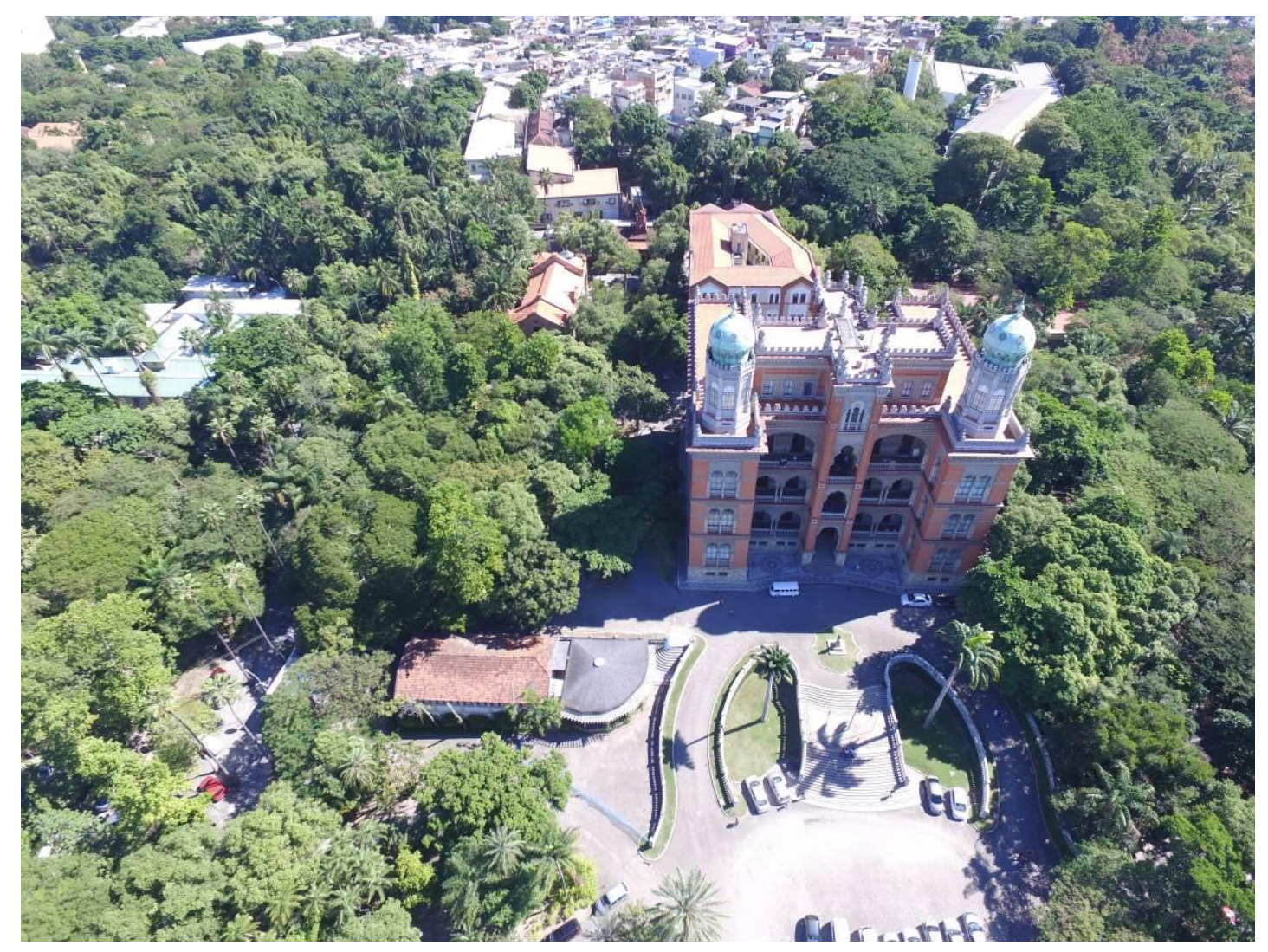

Figura 1 - Foto do Núcleo Arquitetônico Histórico Manguinhos, feita com o drone Fonte: DPH (2018)

\section{SISTEMA DE INFORMAÇÕES SOBRE O ACERVO ARQUITETÔNICO DA FIOCRUZ}

A organização dos dados em um sistema de informação é fundamental para dar suporte à gestão da conservação. Em 2008, o DPH implementou o Sistema Integrado de Gestão da Manutenção - SIGMA, uma ferramenta de controle, planejamento do trabalho e auxílio nas tarefas de conservação-manutenção. A intenção foi sistematizar as demandas de serviço mediante a geração de "Ordens de Serviço" (O.S). Pelo sistema adotado, uma OS é emitida antes do começo de cada trabalho, permitindo controle dos processos e registro das informações (MENDES, 2018).

As O.S's preventivas de manutenção predial (civil) são programadas por períodos e abertas automaticamente pelo sistema, respeitando a periodicidade definida. Para ações típicas da área de conservação, como limpeza de revestimentos, etc. a programação das ações é realizada manualmente a partir dos dados resultantes das atividades de monitoramento ou por demandas emergenciais. 
Em 2010 foi iniciado pelo DPH o projeto intitulado "Organização dos inventários do patrimônio arquitetônico da Fiocruz", cujo objetivo era criar uma ferramenta para organização das informações históricas e técnicas sobre as edificações de interesse histórico do campus Manguinhos. Para a construção e agrupamento de dados históricos e dados cadastrais do acervo edificado foram consultadas diversas fontes, tais como publicações científicas, acervo do Departamento de Arquivo e Documentação/Fiocruz e acervo técnico do $\mathrm{DPH}$, composto por documentos gerados pela equipe do departamento a partir do final da década de 1980.

O modelo de fichas - de "inventário" e de "projetos e obras" - partiu de uma investigação de outros modelos de inventário, como as do IPHAN e INEPAC, e adaptados ao acervo técnico do DPH. As fichas de inventário relacionam aspectos cadastrais básicos, como denominação, data de construção, autor do projeto, metragem, aspectos formais e históricos. Já as fichas de projetos e obras destacam dados gerais sobre as intervenções que geraram documentação administrativa. Assim, ficam de fora as ações rotineiras das obras de manutenção.

Ao final de quatro anos, como resultado, foram construídas 14 grupos de fichas das edificações: Pavilhão Mourisco; Cavalariça; Pavilhão do Relógio; Quinino; Casa de Chá e Anexo; Hospital Evandro Chagas; Casa Amarela; Pombal; Pavilhão Arthur Neiva; Pavilhão Carlos Augusto da Silva; Portaria da Av. Brasil; Pavilhão Henrique Aragão; Pavilhão Rockefeller; e jardins de interesse histórico do campus.

Devido ao aumento de edificações sob sua responsabilidade e a demanda de serviços (projetos ou operações de rotina) a equipe do DPH tem verificado a necessidade de refletir sobre seus processos de trabalho, tanto no que tange à consulta a informações técnicas/históricas, à produção de novos dados e ao tipo de armazenamento. Atualmente as informações relativas ao estado de conservação e procedimentos de conservação adotados nas edificações encontra-se dispersa nos diversos tipos de documentos produzidos pelas equipes - relatórios, diários de obra, ordens de serviço, fotografias. Assim, ainda é uma demanda a criação e implementação de um modelo que unifique todos os registros referentes ao estado de conservação dos elementos construtivos das edificações. Tal ferramenta contribuirá para o desenvolvimento de projetos de restauração e elaboração dos planos de conservação preventiva para as edificações históricas.

\section{ADAPTAÇÕES DE FERRAMENTAS PARA MONITORAMENTO}

\subsection{Ações de inspeção com drone}

Os drones, inicialmente considerados instrumentos para missões militares, temse revelado importantes aliados nos esforços de conservação de edificações. Eles apresentam vantagens como a capacidade de monitorar áreas antes consideradas fora do alcance, reduzindo custos e riscos à vida humana e ao patrimônio.

Um problema comum nas edificações de interesse histórico do NAHM diz respeito à acessibilidade aos entreforros e coberturas. É essencial executar rotinas de manutenção para monitorar adequadamente o sistema de 
cobertura evitando infiltrações, e ao mesmo tempo viabilizar o acesso com segurança e respeitando a legislação de trabalho em altura.

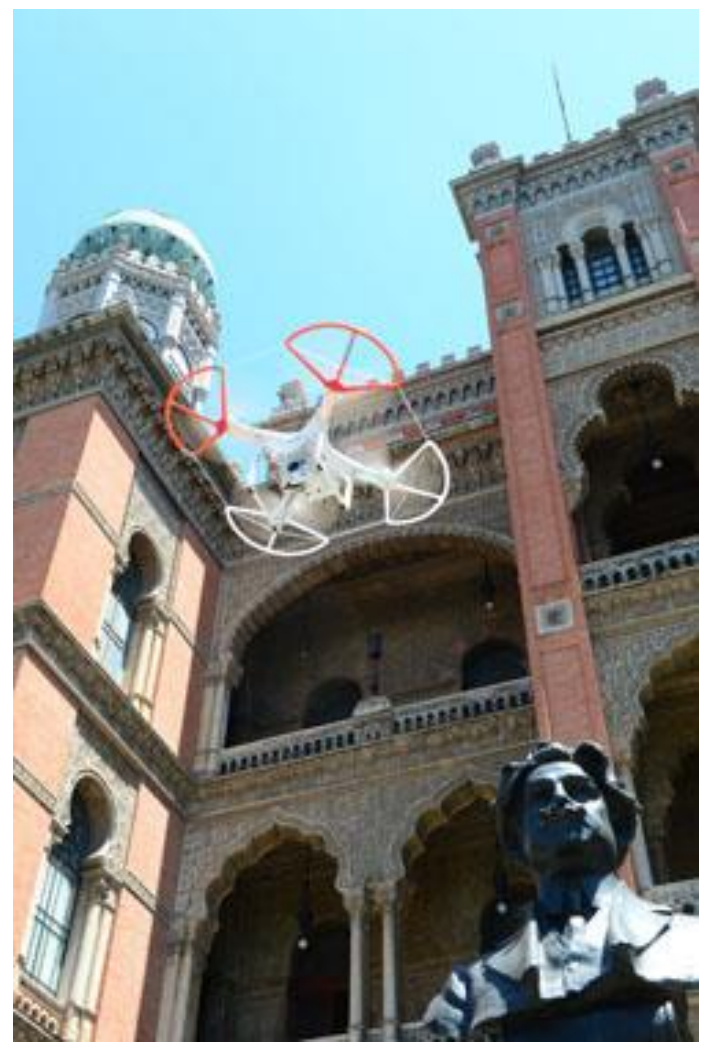

Figura 2 - Uso do drone em inspeções visuais Foto: Peter llicciev - CCS/Fiocruz

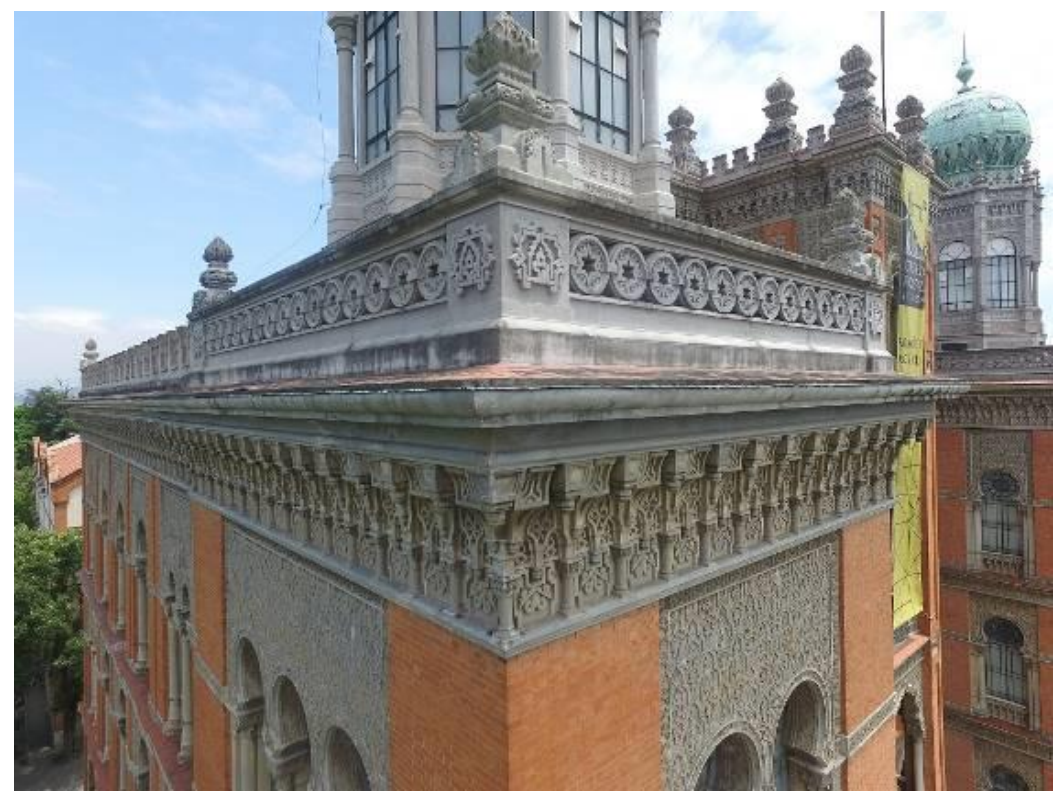

Figura 3 - Inspeção nos elementos de cobertura realizada com o uso de drone no Pavilhão Mourisco -

Fonte: DPH (2018)

O equipamento vem sendo usado principalmente para a realização de inspeções em elementos de cobertura e coroamento das edificações históricas de difícil acesso [Figuras 2 e 3]. Sua utilização gera um acervo 
considerável de vídeos e imagens cuja organização precisa estar interligada aos outros tipos de documentos gerados pela equipe.

Visando aprimorar as estratégias de monitoramento o DPH adquiriu um drone modelo Phantom 3 Professional com câmera de resolução 4K que gera imagens de alta resolução em foto e vídeo. Considerando as normas de segurança para utilização de drones seis pessoas da equipe receberam treinamento específico que incluiu curso de pilotagem e aulas teóricas sobre as normas que regulamentam sua utilização.

\subsection{Implantação de novas ferramentas}

Apesar das vantagens oferecidas pelo uso dos drones foi averiguado que sua adoção como ferramenta de suporte ao monitoramento ainda não solucionava todas as questões relacionadas à acessibilidade aos elementos e espaços das edificações e jardins históricos do NAHM, especialmente às áreas de dimensões reduzidas e fechadas - tais como túneis, pavimentos técnicos e entreforros. Por esse motivo encontra-se em fase de testes a implementação de um veículo de controle remoto com três câmeras a ser adotado para o monitoramento de locais de dimensões reduzidas. O veículo possui um sistema de suspensão e um sistema mecânico que permite forte tração nas rodas, o que permite passar por obstáculos com facilidade e o que também ajuda a vencer os obstáculos.

O controle remoto do veiculo tem alcance de até quinhentos metros e as câmeras têm lentes de grande ângulo permitindo assim que o carro possa ser pilotado remotamente com precisão. Existe também um sistema de chaveamento das câmeras permitindo que, do ponto de vista do veículo, a qualquer momento se tenha visão frontal, superior e traseira. Todas as imagens ficam disponíveis em um monitor de vídeo e é através desse monitor que a pilotagem do veículo pode ser feita [Figura 4]. A transmissão das imagens para o monitor é feita por sistema sem fio com alcance em torno de quinhentos metros. A resolução das câmeras é suficiente para que se tenham imagens de qualidade. Entretanto é possível instalar no sistema câmeras de alta resolução $4 \mathrm{~K}$, permitindo assim uma ampliação das possibilidades do uso das imagens em softwares de junção de imagens e fotogrametria.

A imagem das câmeras é gravada em cartões de memória permitindo assim, de acordo com a capacidade do cartão, gravações de até uma hora de duração. O veículo concebido tem equipamentos de média qualidade, mas como perspectiva para o futuro existe a possibilidade de montagem de um veículo com alto nível de controle e inclusive com sistema de GPS, ampliando mais ainda as possibilidades de uso das imagens adquiridas com o sistema.

O primeiro trabalho realizado foi a filmagem do entreforro do $3^{\circ}$ pavimento do Pavilhão Mourisco visando levantar dados que possam subsidiar o projeto de intervenção na cobertura da edificação, que apresenta hoje problemas de estanqueidade. O espaço do entre forro é de difícil acesso por pessoas, inclusive com risco de acidente de trabalho. Os testes realizados foram bem sucedidos, pois o veículo conseguiu vencer todos os obstáculos e obter imagens com qualidade suficiente para observar algumas patologias que apontam para infiltrações. Foi possível também observar o estado geral do ambiente (Figuras 5 e 6). 


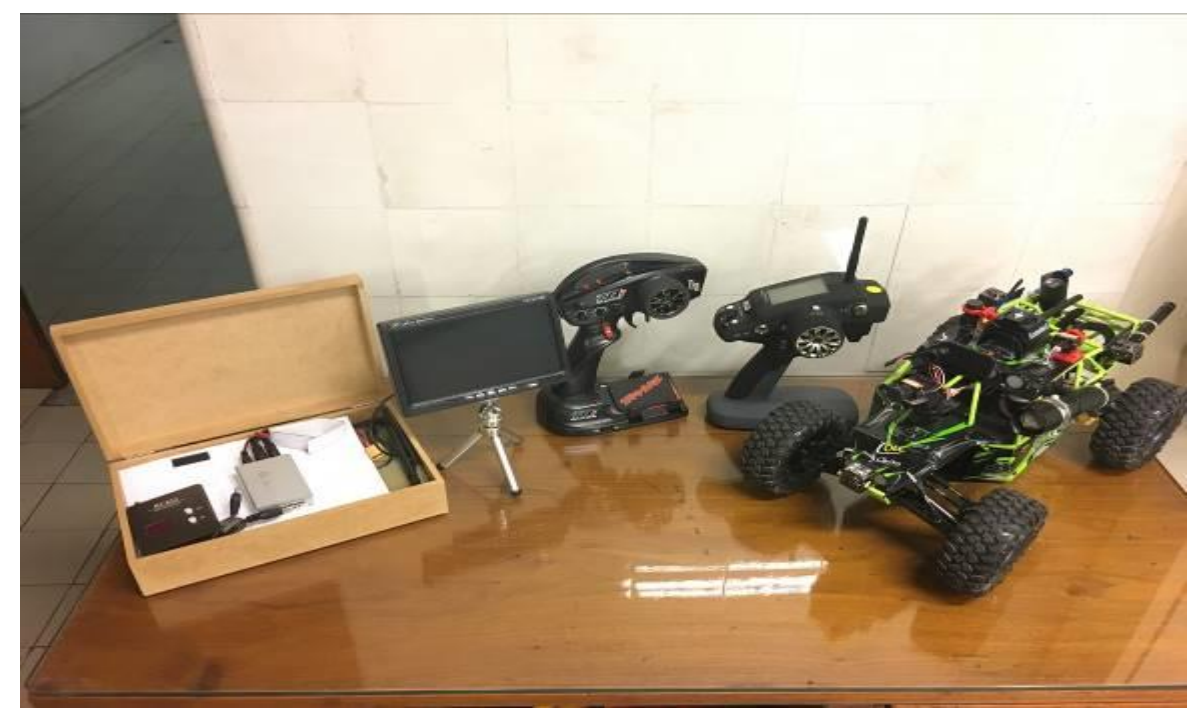

Figura 4 - Veículo de controle remoto e acessórios Fonte: DPH (2019)

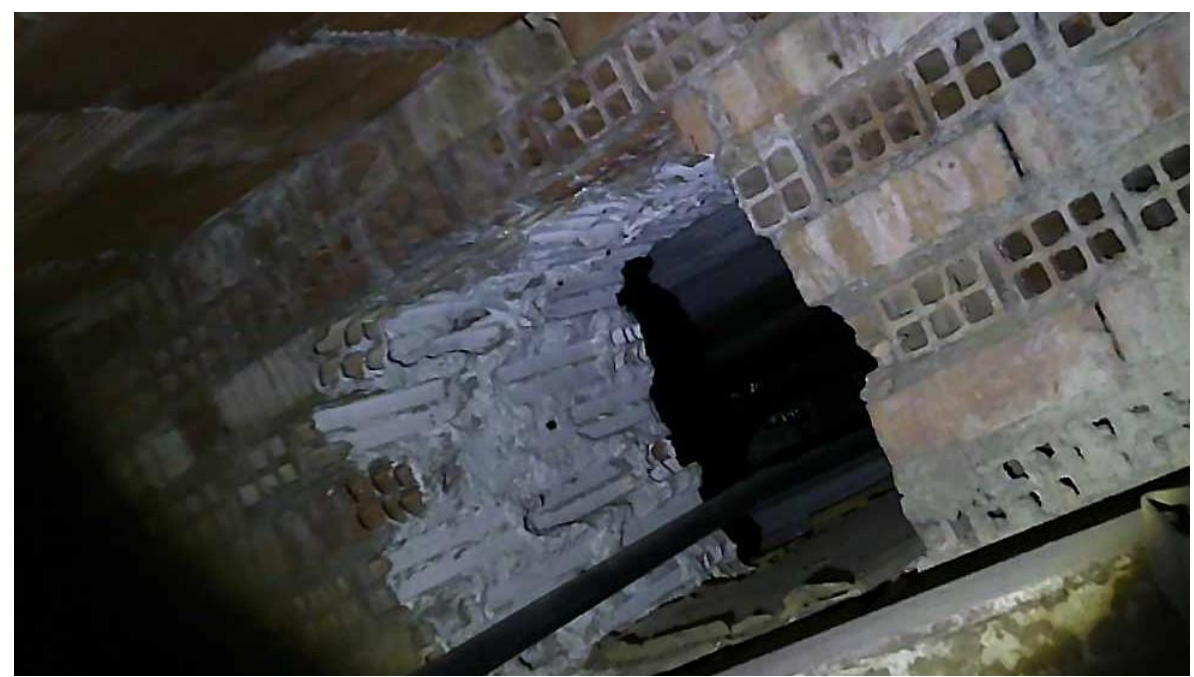

Figura 5 - Vistoria teste em entreforro do $3^{\circ}$ pavimento do Pavilhão Mourisco Fonte: DPH (2019)

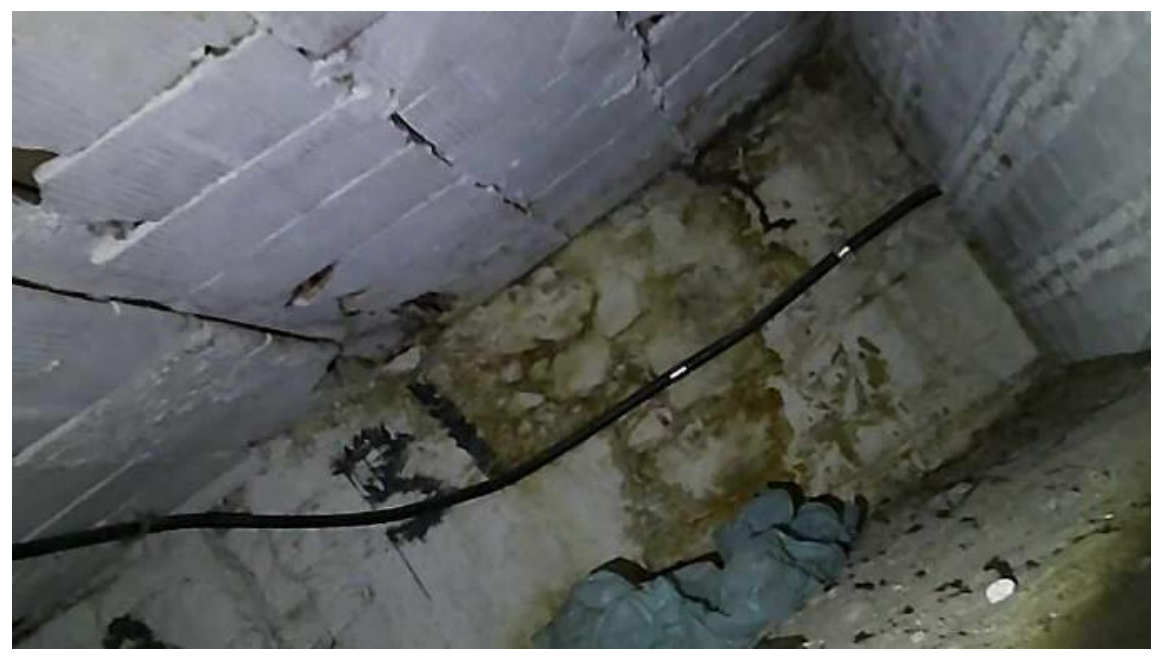

Figura 6 - Vistoria teste em entreforro do $3^{\circ}$ pavimento do Pavilhão Mourisco Fonte: DPH (2019) 
Continuando as atividades de teste do veículo com câmeras, foi realizado um trabalho de filmagem em um poço aquífero que se estima ter feito parte de um sistema de armazenamento de água utilizado pela antiga fazenda de Manguinhos. Convém destacar que o atual campus Fiocruz Manguinhos tem sua origem no sítio histórico dessa antiga fazenda. A Fazenda de Manguinhos, com cerca de 3.500 metros quadrados (DIAS, 1918, p.8), foi uma prospera unidade produtora de café durante a primeira metade do século XIX e conectava-se ao caminho do antigo Caminho do Porto de Inhaúma.

O objetivo do trabalho realizado foi levantar dados que possam revelar como é o abastecimento e esgotamento do poço de interesse histórico na atualidade, isto é, identificar redes que se ligam ao poço. Essa investigação, em parceria com a Coordenação-Geral de Infraestrutura dos Campi (Cogic), está vinculada com outros estudos sobre a qualidade da água, poderá dar subsídios para o aproveitamento desse poço para a rega dos jardins do campus. O poço é bastante profundo e de difícil acesso por profissionais. Para realização da inspeção o veículo com câmeras foi suspenso por duas cordas, para garantir estabilidade, e abaixado até o fundo do poço (Figura 7).

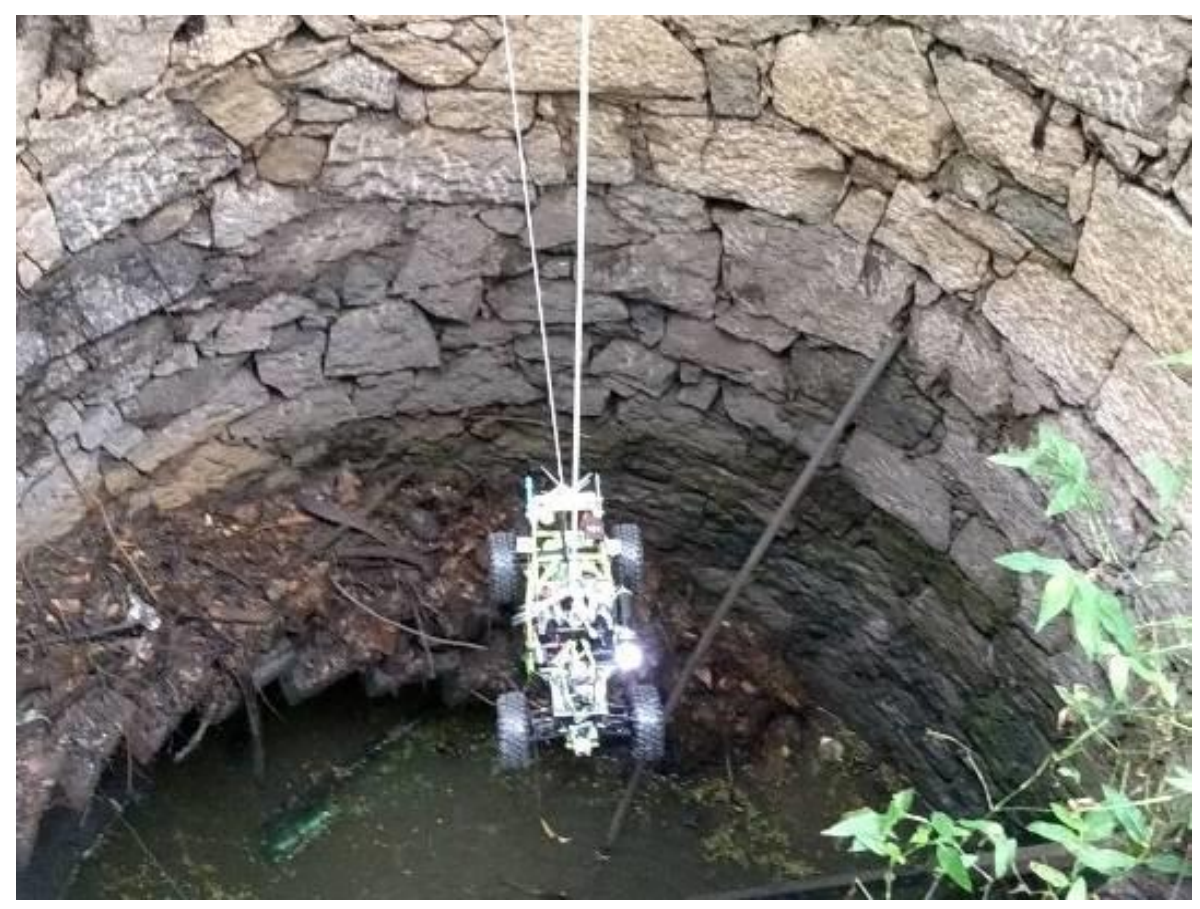

Figura 7 - Vistoria teste em poço de interesse histórico no NAHM Fonte: DPH (2019)

O veículo apresenta-se como uma ferramenta viável e que pode apresentar outros resultados muito relevantes relacionados ao levantamento de dados para estudos históricos, projetos de restauração e procedimentos de conservação preventiva.

\section{FOTOGRAMETRIA DIGITAL E ESCANEAMENTO A LASER}

O uso de outras novas tecnologias focados na produção de documentação gráfica mais detalhada e para a investigação do estado de conservação está sendo explorado pela equipe do DPH. O departamento produziu ao longo de sua existência um robusto e imprescindível acervo de levantamentos 
arquitetônicos de seu patrimônio edificado. No entanto, com o objetivo de ajustar as imprecisões em decorrência do método usual, o uso de tecnologias digitais como a varredura a laser e fotogrametria $3 d$ são opções para uma reconstrução digital fidedigna das edificações, com precisão variando de milímetros à centímetros (CANUTO; MOURA; SALGADO, 2016).

A fotogrametria digital tem como objetivo "a geração de informação métrica e descritiva de uma superfície ou objetos fotografados, a partir de técnicas fotogramétricas que utilizam uma imagem singular ou um conjunto de imagens" (RESENDE, 2008). O processo envolve a tomada de ortofotos em alta resolução com a definição de pontos de articulação, parâmetros geométricos e coordenadas, para posterior processamento em softwares específicos.

Atualmente estão em cursos contratações de serviços especializados de fotogrametria digital das fachadas do Pavilhão Mourisco e de levantamento por meio da tecnologia de escaneamento a laser do edifício da Cavalariça. A execução do serviço está programada para ser realizada em três etapas; a primeira consiste no trabalho de campo, na qual serão tomadas fotografias niveladas dos elementos arquitetônicos em dois níveis (de conjunto e de detalhamento); a segunda etapa é a de fotogrametria aérea, com a tomada de fotos aéreas com o uso de drones; e finalmente o trabalho interno, que consiste na restituição e correção de cada foto com uso de programas apropriados, montagem do modelo 3D e geração de ortofotos com alta precisão métrica.

O levantamento por fotogrametria digital do Pavilhão viabilizará o fornecimento de subsídios aos projetos necessários por meio do registro em imagens de alta definição e representações gráficas precisas; o registro do estado de conservação dos seus elementos e a elaboração de mapeamentos detalhados, diagnósticos mais completos; e consequentemente, o planejamento prévio mais preciso para futuras intervenções.

A técnica de escaneamento tridimensional a laser, também conhecido como 3D laser scanning, é uma ferramenta de levantamento que utiliza equipamentos especiais de varredura tridimensional a laser de superfícies para a geração de modelos geométricos tridimensionais. Tem como produto a representação gráfica e das características físicas e geométricas internas e externas do edifício de forma detalhada e rigorosa em desenhos 2D e 0 modelo 3D da edificação.

O levantamento tridimensional a laser tem como base a obtenção, por meio de equipamento de varredura espacial (scanner 3D), da chamada "nuvem de pontos", que se caracteriza pela junção em um único sistema de coordenadas, de todos os pontos medidos pelos equipamentos, permitindo a identificação das as superfícies com alto nível de precisão.

O processo previsto compreende uma etapa de emissão da nuvem de pontos em cor real, com o uso de alvos e a definição de pontos de referências, que servirão para a articulação das cenas, seguido pela etapa de trabalho em escritório, na qual a novem de pontos deverá ser convertida em desenhos 2D e modelo 3D.

A escolha do uso dessa técnica na Cavalariça se deu em razão de sua atual desocupação, viabilizando a varredura de todos seus elementos internos, uma vez que não há no seu interior objetos que provoquem interferência à leitura 
do scanner. As informações coletadas permitirão a consolidação de levantamento cadastral com grande precisão, fornecendo uma base confiável para a realização de projetos e, posteriormente, para embasar as ações de conservação preventiva.

\section{CONSIDERAÇÕES FINAIS}

O presente trabalho buscou apresentar as diferentes ações em andamento voltadas para o aprimoramento das ferramentas de monitoramento e do sistema de informação relativos aos edifícios históricos da Fiocruz. Tais iniciativas visam à melhoria da qualidade e eficácia das ações rotineiras de conservação e dos projetos de intervenção desenvolvidos pela equipe.

O tipo e quantidade de dados necessários para alimentar o planejamento das ações preventivas difere daqueles tradicionalmente usados para projetos de restauração na medida em que precisam ser coletados periodicamente e armazenados de forma a garantir aos técnicos uma visão abrangente sobre os diferentes problemas observados nas edificações históricas ao longo do tempo.

As perspectivas futuras indicam a necessidade de elaboração de um banco de dados unificado seguindo a abordagem proposta pela tecnologia BIM Building Information Modeling capaz de articular os diferentes tipos de informação geradas pelas ações sob responsabilidade da equipe, facilitando cada vez mais sua utilização para retroalimentar os processos de trabalho, embasar análises de riscos e facilitar a disponibilização de dados para público externo.

No Brasil, a tecnologia BIM tem sido adotada em escritórios de arquitetura e engenharia para o gerenciamento integrado de projetos. Sua aplicação ao patrimônio edificado e estruturas arqueológicas - chamado de Historical Building Information Modeling ou H-Bim - como suporte para agrupar as informações técnicas não foi ainda explorada como no âmbito internacional. O H-BIM dá ênfase ao conhecimento geométrico e história do edifício. Modela não só o edifício como também os seus bens integrados e os materiais constituintes (RAMOS et al., 2017). Auxilia na avaliação do estado de conservação e representa um catalogo orientado para documentação e planejamento das intervenções de conservação.

Está em processo de implementação pelo DPH/COC um laboratório voltado para a prática de ações de conservação preventiva. A intenção é que o novo espaço proporcione o compartilhamento de saberes entre os especialistas do DPH, contribuindo para a investigação e reflexão dos processos de trabalho conduzidos pelo departamento. Isto inclui a discussão de resultados das investigações de conservação programada, a criação de modelos de fichas de inspeção e a criação de plataformas unificadas de banco de dados.

\section{REFERÊNCIAS}

CANUTO, C. L; MOURA, L. R; SALGADO, M. S. Tecnologias digitais e preservação do patrimônio arquitetônico: explorando alternativas. Parc, Pesquisa em

Arquitetura e Construção, Campinas, SP, v.7, n.4, p.252-264, dez. 2016. 
DIAS, E. O Instituto Oswaldo Cruz: resumo histórico (1899-1918). Rio de Janeiro: Manguinhos, 1918.

FUNDAÇÃO OSWALDO CRUZ. CASA DE OSWALDO CRUZ. Política de Preservação e Gestão de Acervos Culturais das Ciências e da Saúde da Casa de Oswaldo Cruz - Fiocruz. Rio de Janeiro: Fiocruz/COC, 2013. Disponível em: <wwW.coc.fiocruz.br>. Acesso em: 01 out. 2019.

MENDES, F. A conservação programada do pavilhão do relógio: estratégias para a preservação de um bem cultural. 141f. 2018. Dissertação (Mestrado em Preservação e Gestão do Patrimônio Cultural das Ciências e da Saúde) - Casa de Oswaldo Cruz da Fundação Oswaldo Cruz, Rio de Janeiro, 2018.

PINHEIRO, M. J. A.; LOURENÇO, B. C. G.; DUARTE, M. C. C.; FRANQUEIRA, M. L.; LOPES, D. S. Metodologia e Tecnologia na área de manutenção e conservação de bens edificados - o caso do Núcleo Arquitetônico Histórico de Manguinhos. Rio de Janeiro: Fiocruz - Casa de Oswaldo Cruz, 2009.

RAMOS, L. F.; MORAIS, M.; AZENHA, M.; MASCIOTTA, M.; PEREIRA, E.; FERREIRA, T.; LOURENÇO, P. Monitorização e Conservação Preventiva do Património Histórico: o Projeto HeritageCare. In: COSTA, A.; VELOSA, A.; TAVARES, A. Congresso da Reabilitação do Património. Portugal: Universidade de Aveiro, 2017. P. 297-306.

RESENDE, W. S. Fotogrametria Digital e Patrimônio Histórico: Uma Proposta Metodológica. ifORUM PATRIMÔNIO: amb. constr. e patr. sust., Belo Horizonte, v.2 , n.2, mai. /ago. 2008. 